\title{
Experimental Research on Fuel Oil Corrosion Resistance of Asphalt Mixtures
}

\author{
LI Qiang ${ }^{1}$, Zhang Zhuoyu ${ }^{1}$, and $L I \mathrm{Ke}^{1}$ \\ ${ }^{1}$ School of Civil Engineering, Nanjing Forestry University, Nanjing, Jiangsu 210037, China
}

\begin{abstract}
Asphalt mixtures were immersed in the fuel oil to study the oil corrosion resistance. The mechanical performance of asphalt mixtures in the oil was evaluated by the observation, mass loss measurement, Marshall stability test and splitting strength test. Effects of immersion time, binder types, and anti-oil corrosion additive content were analyzed. It is found that there is the evident stripping after immersing the mixture in the oil. The stability test and strength significantly decrease. Using the anti-oil corrosion additive can effectively improve the mechanical performance of asphalt mixtures in the oil. It still can satisfy the criteria after immersing for 7 days. Finally, the optimum anti-oil corrosion additive content of $0.4 \%$ is recommended.
\end{abstract}

\section{Introduction}

In recent years, the traffic volume of road has increased greatly, and some overload vehicle run in poor condition, which is easy to cause oil leakage ${ }^{[1-2]}$. Asphalt is mainly composed of alkanes, cycloparaffins, aromatic hydrocarbons and their derivatives, which are easily soluble in organic solvents such as diesel and gasoline ${ }^{[3]}$. When the oil is in contact with the asphalt pavement, it is easy to dissolve the asphalt, causing the asphalt film to peel off from the surface of the aggregate ${ }^{[4-5]}$. Therefore, oil corrosion resistance is an important road performance of asphalt mixture.

The anti-oil corrosion property of asphalt mixture was studied by different scholars. Zhang rui and Huang xiaoming $^{[6]}$ analyzed various occasions where fuel oil could leak, and respectively tested the mass loss, hightemperature performance (rutting test) and splitting strength of matrix asphalt mixture and SBS modified asphalt mixture after immersion in oil. Li pei et $\mathrm{al}^{[7]}$ improved the oil corrosion resistance of asphalt mixture by adding modifier, and verified the pavement performance of modified asphalt mixture. Li shanqiang and $\mathrm{Li} \mathrm{hao}{ }^{[8]}$ proposed the test method of fuel oil corrosion, and evaluated the oil corrosion resistance of different types of asphalt mixtures through Marshall stability test under oil corrosion conditions, immersion Marshall stability test, Kentaberg dispersion test and wheel rutting test. In this paper, the oil corrosion resistance of two different types of asphalt mixtures was evaluated by the apparent change, mass loss, Marshall stability test and splitting strength test under the condition of oil immersion.

\section{Test program}

\subsection{Raw material and mix proportion design}

Two kinds of asphalt mixtures were selected for oil corrosion resistance test. Among them, AC-13C mixture is $\mathrm{AC}-13$ grade + basalt aggregate $+70 \#$ matrix asphalt, and $\mathrm{AC}-13 \mathrm{M}$ mixture is $\mathrm{AC}-13$ grade + basalt aggregate +SBS modified asphalt. The main technical properties of asphalt are shown in table 1, the main technical properties of aggregate are shown in table 2, and the aggregate gradation is shown in figure 1 .

Table 1. Asphalt binder properties.

\begin{tabular}{|c|c|c|c|c|}
\hline \multirow{2}{*}{ Test programs } & \multicolumn{2}{|c|}{ 70\#Matrix asphalt } & \multicolumn{2}{|c|}{ SBS modified asphalt } \\
\hline & Measured & Required & Measured & Required \\
\hline Density $\left(15^{\circ} \mathrm{C}\right) /\left(\mathrm{g} / \mathrm{cm}^{3}\right)$ & 1.022 & Measured & 1.026 & Measured \\
\hline needle penetration $\left(25^{\circ} \mathrm{C}\right) / 0.1 \mathrm{~mm}$ & 69 & $60 \sim 80$ & 53 & $40 \sim 60$ \\
\hline softening point $/{ }^{\circ} \mathrm{C}$ & 52 & $\geq 46$ & 78 & $\geq 60$ \\
\hline ductility (matrix asphalt $15^{\circ} \mathrm{C} /$ modified asphalt $5^{\circ} \mathrm{C}$ ) $/ \mathrm{cm}$ & $>100$ & $\geq 100$ & 32.5 & $\geq 20$ \\
\hline dynamic viscosity $\left(60^{\circ} \mathrm{C}\right) /(\mathrm{Pa} \mathrm{s})$ & 1551 & $\geq 180$ & 24000 & \\
\hline
\end{tabular}

\footnotetext{
Li Qiang: liqiang2526@njfu.edu.cn
} 


\begin{tabular}{|l|l|l|l|l|l|}
\hline \multirow{3}{*}{ RTFOT } & quality loss $/ \%$ & -0.14 & $-0.8 \sim+0.8$ & -0.05 & $-1.0 \sim+1.0$ \\
\cline { 2 - 6 } & Residual injection ratio $/ \%$ & 68.1 & $\geq 61$ & 77.0 & $\geq 65$ \\
\cline { 2 - 5 } & $\begin{array}{l}\text { Residual ductility (matrix asphalt } 15{ }^{\circ} \mathrm{C} / \\
\text { modified asphalt } 5{ }^{\circ} \mathrm{C} \text { ) } / \mathrm{cm}\end{array}$ & 9.0 & $\geq 6$ & 25 & $\geq 15$ \\
\hline
\end{tabular}

Table 2. Coarse aggregate properties.

\begin{tabular}{|l|l|l|l|}
\hline Test programs & $\begin{array}{l}4.75 \sim 13.2 \\
\mathrm{~mm} \\
\text { particle } \\
\text { size }\end{array}$ & $\begin{array}{l}2.36 \sim 4.75 \\
\mathrm{~mm} \\
\text { particle } \\
\text { size }\end{array}$ & $\begin{array}{l}\text { Technical } \\
\text { standard }\end{array}$ \\
\hline Soft grain in aggregate/\% & 0.4 & $/$ & $\leq 3$ \\
\hline $\begin{array}{l}\text { Apparent relative density / } \\
\left(\mathrm{g} / \mathrm{cm}^{3}\right)\end{array}$ & 2.730 & 2.778 & $\geq 2.60$ \\
\hline $\begin{array}{l}\text { Bulk volume relative density } \\
/\left(\mathrm{g} / \mathrm{cm}^{3}\right)\end{array}$ & 2.707 & 2.740 & $/$ \\
\hline Crushing value/\% & 18.9 & $/$ & $\leq 26$ \\
\hline Sediment percentage/\% & 0.3 & 0.5 & $\leq 1.0$ \\
\hline Needle like content $\%$ & 4.7 & $/$ & $\leq 15$ \\
\hline
\end{tabular}

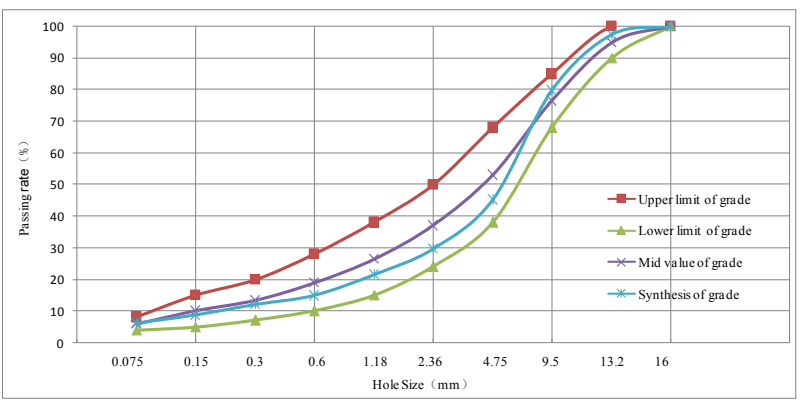

Fig. 1. Aggregate gradation curve.

Using PR $\mathrm{AK}^{\circledR}$ modifier to improve the oil corrosion resistance of asphalt mixture, the product is black powder, the particle diameter is between $0 \sim 1200$ microns, which can be stored for a long time under room temperature, and suitable for all kinds of asphalt and aggregate type. It is easy to add which adopted direct investment production technology. Anti-oil corrosion additive was only added to the $\mathrm{AC}-13 \mathrm{C}$ mixture, and the dosage was respectively $0 \%$ (no mixing), $0.2 \%, 0.4 \%$ and $0.6 \%$ of the total mass of the mixture, and a comparative study was conducted with the AC-13M mixture without addition of anti-oil corrosion additive. The best asphalt-aggregate ratio of both asphalt mixtures was $5.0 \%$ with Marshall design method.

\subsection{Oil-impregnated treatment}

The oil immersion vessel is a translucence plastic container which is quadrangular shape. After the standard Marshall test piece was putted into the container, add $500 \mathrm{ml}$ No. 0 fuel oil. First, the oil corrosion resistance of the asphalt mixture was evaluated from the aspect of appearance. Taking out the immersion test piece every day to observe the apparent change, and measuring the quality change of the test piece after being dried to constant weight by the blower. The total immersion time was 7 days. The calculation formula of mass loss rate is shown in formula (1).

$$
l=\left(M_{0}-M_{1}\right) * 100 / M_{0}
$$

Where, $l$ is mass loss rate $/ \%, M_{0}$ is the mass of specimens before oil immersion $/ \mathrm{g}, M_{1}$ is the mass of specimens after oil immersion $/ \mathrm{g}$.

\subsection{Oil immersion Marshall stability test}

Compared the Marshall stability of asphalt mixture specimens with immersion oil before and after $60{ }^{\circ} \mathrm{C} . r_{\mathrm{ms}}$ of residual stability ratio after oil immersion is defined as the evaluation index, the calculation formula is shown in formula (2).

$$
r_{\mathrm{ms}=} m s_{1} / m s_{0}
$$

Where, $r_{\mathrm{ms}}$ is the residual stability ratio after oil immersion. $m s_{0}$ is the Marshall stability of the specimens before oil immersion/KN; $m s_{1}$ is the Marshall stability of the specimens after oil immersion/KN.

\subsection{Oil immersion test for splitting strength}

The splitting strength of the asphalt mixture Marshall specimens before and after oil immersion was tested under the temperature of $20{ }^{\circ} \mathrm{C}$ and the loading rate level of $50 \mathrm{~mm} / \mathrm{min}$. Define the residual strength ratio after oil immersion as an evaluation index, The calculation formula is shown in formula (3).

$$
r_{\mathrm{ss}}=s s_{1} / s s_{0}
$$

Where, $r_{\mathrm{ss}}$ is the residual strength ratio after oil immersion, $s s_{0}$ is the splitting strength of the specimens before oil immersion/MPa, $s s_{1}$ is the splitting strength of the specimens after oil immersion/MPa.

\section{Analysis of test results}

\subsection{Loss of appearance and quality}

The apparent change of various types of asphalt mixtures under different oil immersion time is shown in figure 2 . It can be seen from the figure that the matrix asphalt mixture (AC-13C- $0 \%$ ) without the addition of anti-oil corrosion additive soaked in the diesel for 1 day, the surface and corner of the test piece began to lose grain. With the time of oil immersion increases, the bitumen dissolves rapidly, and the phenomenon of dropping granules becomes more and more serious. When the oil immersion time reaches 7 days, the surface of the test piece will appear empty, leaving only the skeleton of coarse aggregate, a lot of flaking of asphalt mortar (the adhesive composed of asphalt, mineral powder and part of fine aggregate), and even white material will appear on the surface after the test piece is blown dry. The SBS modified asphalt mixture (AC-13M- $0 \%$ ) without the addition of anti-corrosion additive also showed obvious peeling on its surface after 7 days of immersion, but the severity was less than that of matrix asphalt mixture. 
However, the surface spalled phenomenon of matrix asphalt mixtures (AC-13C-0.2\%, AC-13C-0.4\% and AC$13 \mathrm{C}-0.6 \%$ ) mixed with anti-oil corrosion additive was significantly relieved after oil immersion, and the adhesion between asphalt and aggregate remained good. Moreover, with the increase of the content of oil corrosion additive, the surface integrity of the specimen gradually increased.

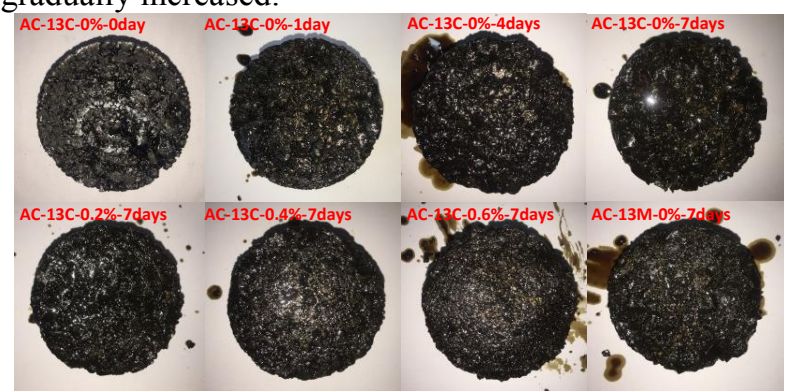

Fig. 2. Appearance change of specimens before and after fuel oil immersion.

The law of the mass loss rate of specimens after oil immersion with the oil immersion time is shown in table 3. It can be seen from the table that the mass loss rate of different asphalt mixtures increases linearly with the increase of immersion time. The mass loss range of common asphalt mixture without anti-oil corrosion additive is the largest, and the average daily mass loss rate is $0.64 \% /$ day. Second, SBS modified asphalt mixture without oil corrosion additive was added, and its average daily mass loss rate was $0.44 \%$ / day. The mass loss of specimens was significantly reduced after the addition of anti-oil corrosion additive. When the dosage was $0.2 \%, 0.4 \%$ and $0.6 \%$, the daily average mass loss rate was $0.36 \%$ / day, $0.18 \% /$ day and $0.14 \%$ / day respectively. Compared with those without anti-oil corrosion additive, the decrease was $43.3 \%, 72.3 \%$ and $77.8 \%$ respectively.

Table 3. Mass loss ratio of asphalt mixtures under different fuel oil immersion days.

\begin{tabular}{|l|l|l|l|l|l|}
\hline \multirow{2}{*}{ Mass loss ratio } & AC- & AC- & AC- & AC- & AC- \\
in different days & $13 C-$ & $13 C-$ & $13 C-$ & $13 C-$ & $13 \mathrm{M}-$ \\
& $0 \%$ & $0.2 \%$ & $0.4 \%$ & $0.6 \%$ & $0 \%$ \\
\hline 0 & 0 & 0 & 0 & 0 & 0 \\
\hline 1 & 1.11 & 0.19 & 0.26 & 0.05 & 0.03 \\
\hline 4 & 3.04 & 1.32 & 0.77 & 0.27 & 1.31 \\
\hline 7 & 4.49 & 2.55 & 1.24 & 1.00 & 3.05 \\
\hline Average & 0.64 & 0.36 & 0.18 & 0.14 & 0.44 \\
\hline
\end{tabular}

\subsection{Immersion Marshall stability}

The results of various types of $60{ }^{\circ} \mathrm{C}$ Marshall stability of asphalt mixture under the condition of different immersion time was shown in figure 3 . It can be found that the Marshall stability of various asphalt mixtures before oil immersion all met the specification requirements ( not less than $8 \mathrm{kN}$ ). However, after oil immersion, the stability of both matrix and SBS modified asphalt mixtures was significantly reduced without the addition of anti-oil corrosion additive. The stability of common asphalt mixtures was lower than $8 \mathrm{kN}$ after 1 day of oil immersion, while that of SBS modified asphalt mixtures was lower than $8 \mathrm{kN}$ after 7 days of oil immersion. The addition of modifier can effectively inhibit the damage of oil corrosion behavior to the high-temperature mechanical properties of asphalt mixture, especially when the content of modifier is not less than $0.4 \%$, its stability is always greater than $8 \mathrm{kN}$ under the condition of oil immersion, and even higher than that of SBS modified asphalt mixture.

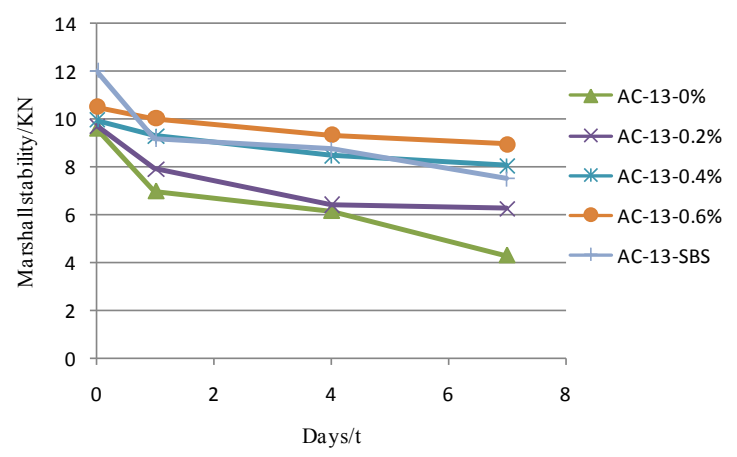

Fig. 3. Marshall stability of asphalt mixtures under different fuel oil immersion days.

It can be seen from figure 4 that although the residual stability ratio of various asphalt mixtures decreases with the extension of oil immersion time, the residual stability ratio of the mixture after the addition of anti-oil corrosion additive is significantly higher than that without anti-oil corrosion additive under the same oil immersion condition. Analysis began after 1 day of oil immersion. With the increase of oil immersion time, the decreasing rate of residual stability ratio of mixture without addition of anti-oil corrosion additive gradually increased, while the performance of mixture with anti-oil corrosion additive was reversed, indicating that addition of modifier could not only weaken but also delay the oil corrosion damage of asphalt mixture. In addition, when the mixing amount is more than $0.4 \%$, the improvement effect of increasing the dosage of modifier is not obvious on the high-temperature mechanical strength of asphalt mixture after oil immersion.

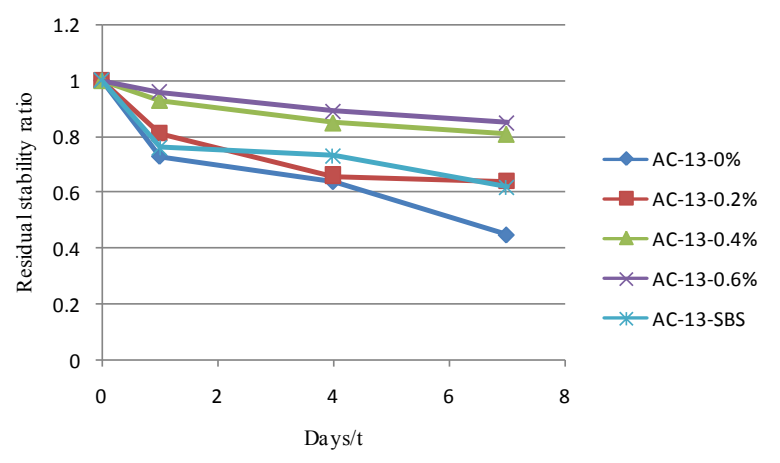

Fig 4. Residual stability ratio of asphalt mixtures under different fuel oil immersion days.

\subsection{The splitting strength of oil immersion}

Various types of asphalt mixture of $20{ }^{\circ} \mathrm{C}$ split strength results under different immersion time was shown in figure 5. It can be found that, similar to the results of Marshall stability test, different types of asphalt mixtures show a declining trend in their splitting strength after oil 
immersion. The reduction in strength of the mixture without oil corrosion inhibitor is significantly greater than that of the mixture with oil corrosion inhibitor. The influence law of oil immersion time on residual strength ratio of asphalt mixture is shown in figure 6 . With the increase of oil immersion time, the residual strength ratio of mixture without addition of anti-oil corrosion additive increased constantly, and the intensity drop of matrix and SBS modified asphalt mixture after 7 days of oil immersion reached $31.2 \%$ and $24.0 \%$ respectively. With the addition of $0.2 \%, 0.4 \%$ and $0.6 \%$ of anti-oil corrosion additive, the splitting strength of matrix asphalt mixture decreased only by $18.6 \%, 12.4 \%$ and $11.8 \%$ respectively, and the decreasing rate decreased .Similarly, increasing the content of modifier from $0.4 \%$ to $0.6 \%$ has no significant effect on further improving the normal temperature mechanical strength of asphalt mixture after immersion in oil.

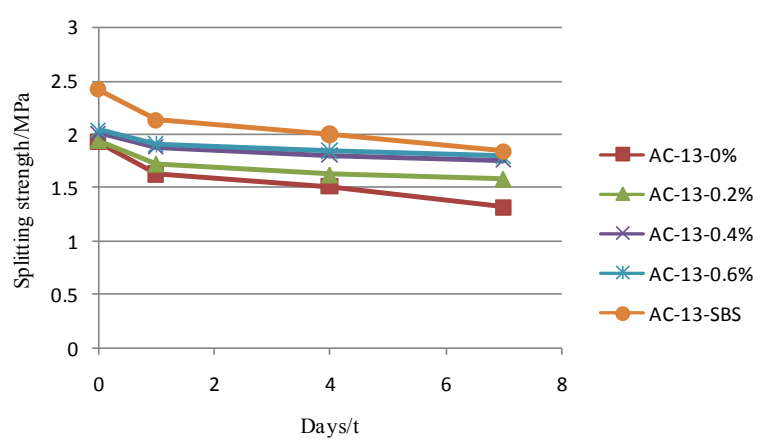

Fig 5. Splitting strength of asphalt mixtures under different fuel oil immersion days/MPa.

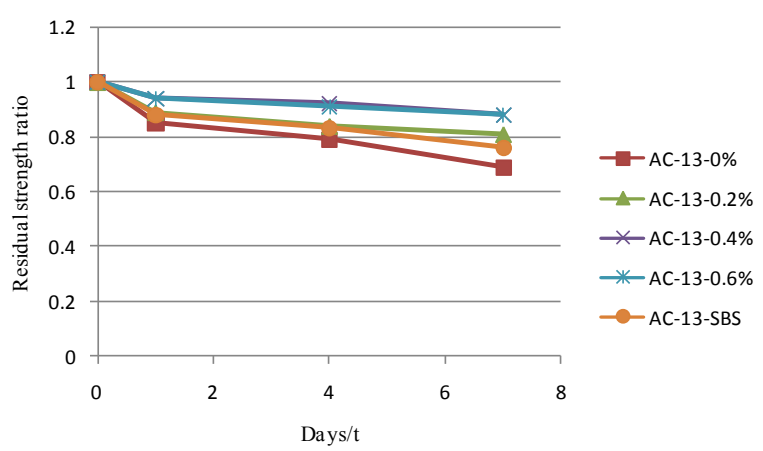

Fig 6. Residual strength ratio of asphalt mixtures under different fuel oil immersion days.

\section{Conclusions}

- No matter matrix asphalt mixture or SBS modified asphalt mixture, the degranulation and surface spalling will occur after oil immersion. With the increase of oil immersion time, the mass loss rate of the mixture increased linearly, and the residual Marshall stability and residual splitting strength continued to decline and the decline rate gradually increased.

- The addition of anti-oil corrosion additive can significantly inhibit and delay the effect of oil corrosion, improve the adhesion between asphalt and aggregate, reduce the mass loss rate of asphalt mixture after oil immersion, improve the residual Marshall stability and residual splitting strength after oil immersion, and reduce the rate of decline of mechanical strength with oil immersion time. After 7 days of immersion, the mechanical properties of matrix asphalt mixture with anti-oil corrosion additive still meet the requirements of the specification.

- The oil corrosion resistance of asphalt mixture was improved with the increase of the content of modifier, but when the content was greater than $0.4 \%$, it had no significant effect to continue to increase the content. Therefore, the optimal amount of anti-oil corrosion additive is $0.4 \%$ after considering the effect and economy.

\section{Acknowledgements}

The authors would like to acknowledge the financial support from the Natural Science Foundation of Jiangsu Province (Grant No. BK20181404), Qing Lan Project, Training Plan Project for Young Core Teachers by Nanjing Forestry University, China.

\section{References}

1. L. G. Anderson. RENEW SUST ENERGREV, 47(2015)

2. T. Fan, J. Paulina, A.Ines. ENVIRON SCI TECHNOL, 49, 12(2015)

3. Z.L.Zhao , J.Q.Guo , P.Yang. Construction Technique, 46, 6(2017)

4. X. K. Yu, G.F. S, M.J. Tao. ENERG FUEL, 32, 1(2018)

5. K. Malal.; E. Vikki. WEAR, 400,4(2018)

6. R.Zhang, X.M.Huang. ROAD, 5:173-176(2006)

7. P. Li, X.B. Li, L.Nie. Construction Technique, 45(2016)

8. S.Q. Li, H. Li. J WUHAN UNIV TECHNOL, 37, $7(2015)$ 